acta medica

\title{
Enthesitis Related Arthritis: A Single Center Experience
}

Selcan Demir ${ }^{1}$, [MD, MSc]

ORCID: 0000-0002-4320-8632

Müşerref Kasap Cüceoğlu', [MD]

ORCID: 0000-0002-9957-8894

Yelda Bilginer', [MD]

ORCID: 0000-0002-6232-0072
${ }^{1}$ Hacettepe University, Faculty of Medicine, Department of Pediatric Rheumatology, Turkey.

Corresponding Author: Selcan Demir Department of Pediatric Rheumatology, Erzurum City Hospital, Erzurum, Turkey.

E-mail: selcandemir@yahoo.com

https://doi.org/10.32552/2021.ActaMedica.624

\section{sel ABSTRACT Cen}

Objective: Enthesitis-related arthritis is a subtype of juvenile idiopathic arthritis category, characterized by enthesitis, arthritis, and the risk of axial involvement. We aimed to summarize the demographics, clinical, and laboratory findings of enthesitis-related arthritis patients and to identify the distinguishing features of enthesitis-related arthritis patients with HLA B27 positive compared to the patients who were HLA B27 negative.

Materials and Methods: This retrospective study included patients with Enthesitis-related arthritis who followed up between 2015 and 2018. Demographical, clinical, and laboratory data were retrospectively reviewed from the patient files and computerized medical charts.

Results: A total of 72 patients diagnosed with enthesitis-related arthritis were included in the study. The male/female ratio was 2.1/1. Fifty-three (73\%) of them presented with peripheral arthritis. The most commonly affected joint was knee (81.1\%), followed by the ankle (43\%), hips (32\%), and wrist (5\%). HLA B27 was positive in $36(50 \%)$ patients. During followup, the number of patients who developed enthesitis-related arthritis -associated uveitis was 8 (11.1\%). During follow-up, 56 patients with inflammatory back pain and/or sacroiliac tenderness underwent spinal MRI. Ten (17.8\%) patients had only thoracal and/or lumbar involvement, $18(32 \%)$ had only sacroiliitis, and $9(16 \%)$ patients had both of them on spinal MRI. In comparison with HLA-B27-negative children, HLAB27-positive patients were more likely to have enthesitis (16 (44.4\%) vs $8(22.2 \%), p=0.046)$, MRI proven sacroiliitis $(19(52.7 \%)$ vs $8(22.2 \%)$, $\mathrm{p}=0.031)$, MRI proven spinal involvement $(13(36.1 \%)$ vs $6(16.6 \%)$, $\mathrm{p}=0.031)$, and uveitis $(8(100 \%)$ vs $0(0 \%), p=0.014)$. During follow up, $65 / 72(90.2 \%)$ of them needed disease-modifying antirheumatic drugs (DMARD), and 51/72 (70.8\%) needed anti-tumor necrosis factor-a (TNF-a) therapy.

Conclusion: We found that patients who were HLA-B27- positive had significantly more enthesitis, MRI-proven sacroiliitis, MRI-proven spinal involvement, and acute anterior uveitis, in comparison to patients who were HLA B27 negative. It is crucial to carefully assess those patients with concern for enthesitis-related arthritis to determine the expected prognosis and make therapeutic decisions appropriately.

Keywords: Juvenile idiopathic arthritis, enthesitis related arthritis, HLA B27 


\section{INTRODUCTION}

Juvenile Idiopathic Arthritis (JIA) is a form of chronic inflammatory arthritis with onset before the age of 16 [1]. According to the classification criteria, proposed by the International League of Associations for Rheumatology (ILAR), JIA is divided into seven subgroups [systemic JIA, oligoarticular JIA, polyarticular rheumatoid factor (RF) negative JIA, polyarticular RF positive JIA, psoriatic arthritis, enthesitis-related arthritis (ERA), and undifferentiated $\mathrm{JI} A$ ] based on the presenting features during the first six months of disease [2].

Enthesitis-related arthritis, which is considered as the pediatric form of adult spondyloarthropathies, has been one of the most controversial subtypes of JIA. However, ERA patients more commonly present with peripheral arthritis, and enthesitis, and less frequently display spinal involvement compared to adult SpA [3]. To diagnose a patient with ERA, it is required the presence of arthritis with enthesitis or the presence of either arthritis or enthesitis and any of the two following features: uveitis, onset in a male child $\geq 6$ years of age, presence of human leucocyte antigen B27 (HLA-B27), presence of either inflammatory low back ache or clinically elicitable tenderness on palpating the sacroiliac joints, or family history of an HLA-B27-associated disease, or acute anterior uveitis in a first-degree relative [2].

In comparison to other categories of JIA, children with ERA tend to have higher disease activity and are also less likely to sustain inactive disease [4]. Standard treatment guidelines for ERA are lacking, and the treatment recommendations for ERA are mainly based on other subtypes of JIA [5]. Recently, ACR recommended not to use methotrexate as a monotherapy for children with sacroiliitis [6].

In this retrospective cross-sectional study, we aimed to summarize the demographics, clinical, and laboratory findings of ERA patients and to identify the distinguishing features of ERA patients with HLA B27 positive compared to the patients who were HLA B27 negative.

\section{MATERIALS and METHODS}

This retrospective study included patients with ERA who followed up between 2015 and 2018. Patients were diagnosed with ERA according to the ILAR criteria [2]. Demographical, clinical, and laboratory data were retrospectively reviewed from the patient files and computerized medical charts. Patients, who followed less than 6 months were excluded. We collected data including gender, age at disease onset, age at diagnosis, clinical features, familial history of autoinflammatory and autoimmune diseases, presence of the HLA-B27 allele, laboratory and radiological tests, any history of uveitis and commitment of Familial Mediterranean Fever. Clinical remission was defined as the absence of symptoms and increased acute phase reactants for at least six months. Ethical approval was obtained from Hacettepe University Institutional Review Board (GO17/652), and was conducted according to the tenets of the declaration of Helsinki.

SPSS software version 25 was used to evaluate the statistical analysis. Continuous data were described as mean, standard deviation (SD), medians, and categorical variables as percentages. The variables were investigated using visual (histogram, probability plots) and analytic methods (Kolmogorov-Smirnov/ Shapiro-Wilk's test) to determine whether or not they are normally distributed. Categorical variables were compared with the chi-square test or Fisher's exact test where appropriate. Student t-test or Mann-Whitney U test was used to compare the continuous data between the two groups where appropriate.

\section{RESULTS}

A total of 72 patients diagnosed with ERA according to the ILAR criteria were included in the study. The male/female ratio was $2.1 / 1$. The median age at disease onset and diagnosis was 10 (IQR:7-13) and 11.5 (IQR: 9.3-14.5) years, respectively. The median follow-up duration was 2.56 (IQR:0.92-4.81) years.

At the time of ERA diagnosis, 53 (73\%) patients had peripheral arthritis, predominantly of the lower limbs. The most commonly affected joint was knee (81.1\%), followed by ankle (43\%), hips (32\%), and wrist (5\%). Fifty-five patients (76.3\%) suffered from morning stiffness longer than 15 minutes and 31 (43\%) from backpain. On the physical examination, enthesitis (achillea or patellar) was detected in 24 (33.3\%) patients, 13 (18.1\%) had positive Schober's 
test and 35 (48.6\%) had sacroiliac tenderness. HLA B27 was positive in $36(50 \%)$ patients and positive family history for HLA-B27-related diseases was present in 28 patients (38.8\%). Out of 72 patients with ERA, 17 (23.6\%) had at least one mutation on MEFV gene, as well. Among patients with FMF there was not a statistically significant difference in terms of HLA B27 positivity ( $p=0.904)$. The vast majority of patients with MEFV gene had sacroiliac involvement and were on anti-TNF treatment $(n=14,82 \%)$. During follow-up, the number of patients who developed ERA-associated uveitis was 8 (11.1\%). All the ERA patients developed acute anterior uveitis were HLA B27 positive. The baseline characteristics of patients were summarized in Table 1.

During follow-up, 56 patients with inflammatory

Table 1. Demographic and baseline clinical characteristics of ERA patients $(n=72)$

\begin{tabular}{|c|c|}
\hline $\begin{array}{l}\text { Age at symptom onset (years) median } \\
\text { (IQR) }\end{array}$ & 10.0 (IQR:7.3-13.5) \\
\hline Age at diagnosis (years) median (IQR) & 11.5 (IQR: 9.3-14.5) \\
\hline Female $n(\%)$ & $23(31.9 \%)$ \\
\hline Male n (\%) & $49(68.1 \%)$ \\
\hline $\begin{array}{l}\text { Positive family history for HLA-B27- } \\
\text { related diseases } \mathrm{n}(\%)\end{array}$ & $28(38.8 \%)$ \\
\hline $\begin{array}{l}\text { Follow-up duration (years) median } \\
(I Q R)\end{array}$ & 2.56 (IQR:0.92-4.81) \\
\hline Morning stiffness n (\%) & $31(43 \%)$ \\
\hline Inflammatory back pain n (\%) & $31(43 \%)$ \\
\hline Enthesitis n (\%) & $24(33.3 \%)$ \\
\hline Positive Schober Test n (\%) & $13(18.1 \%)$ \\
\hline Sacroiliac Tenderness n (\%) & $35(48.6 \%)$ \\
\hline Peripheral joint involvement $\mathrm{n}(\%)$ & $53(73.6 \%)$ \\
\hline Knee n (\%)* & $43 / 53(81.1 \%)$ \\
\hline Hip n (\%)* & $17(32 \%)$ \\
\hline Ankle $\mathrm{n}(\%) *$ & $23 / 53(43 \%)$ \\
\hline Wrist n (\%)* & $5 / 53(5 \%)$ \\
\hline Oligoarticular involvement $\mathrm{n}(\%)^{*}$ & 40 (75.4\%) \\
\hline Polyarticular involvement $\mathrm{n}(\%)^{*}$ & $13(24.5 \%)$ \\
\hline FMF n (\%) & $17(23.6 \%)$ \\
\hline Uveitis n (\%) $)^{* *}$ & $8(11.1 \%)$ \\
\hline HLA-B27 n (\%) & $36(50 \%)$ \\
\hline Hemoglobin $(\mathrm{g} / \mathrm{dl})($ mean $\pm \mathrm{SD})$ & $12.09 \pm 2.02$ \\
\hline Leucocyte $\left(10^{3} / \mathrm{mm}^{3}\right)($ mean $\pm S D)$ & $8600 \pm 3262$ \\
\hline Platelet $\left(10^{3} / \mathrm{mm}^{3}\right)($ mean \pm SD $)$ & $353402 \pm 96848$ \\
\hline CRP $(\mathrm{mg} / \mathrm{dl})($ mean $\pm \mathrm{SD})$ & $5.4 \pm 3.5$ \\
\hline ESR $(\mathrm{mm} / \mathrm{h})($ mean $\pm \mathrm{SD})$ & $33.43 \pm 6.19$ \\
\hline \multicolumn{2}{|l|}{ *Among patients with peripheral involvement } \\
\hline${ }^{* *}$ During follow-up & \\
\hline
\end{tabular}

back pain and/or sacroiliac tenderness underwent spinal MRI. Ten (17.8\%) patients had only thoracal and/or lumbar involvement, 18 (32\%) had only sacroiliitis, and $9(16 \%)$ patients had both of them on spinal MRI. Among them, 15 (26.7\%) patients had both inflammatory and erosive lesions and 22 (39.2\%) patients had only inflammatory lesions on spinal MRI (Table 2).

We compared patient demographics and clinical characteristics of patients on the basis of HLA-B27 status. In comparison with HLA-B27-negative children, HLA-B27-positive patients were more likely to have enthesitis (16 (44.4\%) vs $8(22.2 \%)$, $\mathrm{p}=0.046), M R I$ proven sacroiliitis $(19(52.7 \%)$ vs 8 (22.2\%), $p=0.031), M R I$ proven spinal involvement (13 (36.1\%) vs $6(16.6 \%), p=0.031)$ and uveitis (8 $(100 \%)$ vs $0(0 \%), p=0.014)$. Clinical characteristics of HLA-B27-positive and negative patients are presented in Table 3.

All the ERA patients received nonsteroid antiinflammatory drugs (NSAIDs) at the time of diagnosis. During follow up, 65/72 (90.2 \%) of them needed disease-modifying anti rheumatic drugs (DMARD) (Methotrexate $85 \%$, Sulfasalazine $15 \%)$, and $51 / 72$ (70.8\%) needed anti-tumor necrosis factor- $a$ (TNF- $\alpha$ ) (56.8\% etanercept, 37.2\% adalimumab, $5.8 \%$ infliximab) therapy. The majority of patients who received anti-TNF treatment had spinal involvement (72.5\%). At the last follow-up visit (median 2.56 years, IQR:0.92-4.81), the majority of patients $(66.6 \%, \mathrm{n}=48$ ) were still on DMARD and/or anti-TNF treatment. Twenty-one (29.1\%)

Table 2. Spinal MRI findings and clinical characteristics of ERA patients with axial symptoms at the time of MRI $(n=56)$

\begin{tabular}{|c|c|}
\hline Inflammatory back pain n (\%) & $45(80.3 \%)$ \\
\hline Sacroiliac tenderness $\mathrm{n}(\%)$ & $33(56 \%)$ \\
\hline $\begin{array}{l}\text { Spinal involvement (Thoracal and/or } \\
\text { lumbar) } n(\%)\end{array}$ & $19(33.9 \%)$ \\
\hline $\begin{array}{l}\text { Thoracal involvement on spinal MRI } \\
\mathrm{n}(\%)\end{array}$ & $11(19.6 \%)$ \\
\hline $\begin{array}{l}\text { Lumbar involvement on spinal MRI } \\
\mathrm{n}(\%)\end{array}$ & $14(25 \%)$ \\
\hline Sacroiliitis on spinal MRI n (\%) & $27(48.2 \%)$ \\
\hline Hemoglobin $(\mathrm{g} / \mathrm{dl})($ mean $\pm \mathrm{SD})$ & $12.8 \pm 2.09$ \\
\hline Leucocyte $\left(10^{3} / \mathrm{mm}^{3}\right)($ mean $\pm \mathrm{SD})$ & $7318 \pm 2112$ \\
\hline Platelet $\left(10^{3} / \mathrm{mm}^{3}\right)($ mean $\pm \mathrm{SD})$ & $318125 \pm 124588$ \\
\hline CRP $(\mathrm{mg} / \mathrm{dl})($ mean $\pm \mathrm{SD})$ & $6.9 \pm 2.9$ \\
\hline ESR $(\mathrm{mm} / \mathrm{h})($ mean $\pm \mathrm{SD})$ & $40.27 \pm 22.26$ \\
\hline
\end{tabular}


Table 3. Clinical characteristics of HLA-B27 positive and negative patients

\begin{tabular}{|c|c|c|c|}
\hline & $\begin{array}{c}\text { HLA-B27 positive } \\
(n=36)\end{array}$ & $\begin{array}{c}\text { HLA-B27 negative } \\
(\mathrm{n}=36)\end{array}$ & p-value \\
\hline Age at symptom onset (years) median (IQR) & 10.0 (IQR: 8.5-14) & 9.6 (IQR: $7.5-12$ ) & 0.309 \\
\hline Age at diagnosis (years) median (IQR) & 12.0 (IQR:10-14.5) & 11.0(IQR: 8.8-13.8) & 0.442 \\
\hline Sex (male) n (\%) & $29(80.6 \%)$ & $20(55.6 \%)$ & 0.023 \\
\hline Inflammatory back pain $\mathrm{n}(\%)$ & $17(47 \%)$ & $14(38 \%)$ & 0.115 \\
\hline Enthesitis n (\%) & $16(44.4 \%)$ & $8(22.2 \%)$ & 0.046 \\
\hline Positive Schober Test n (\%) & $9(25 \%)$ & $4(11.1 \%)$ & 0.063 \\
\hline Sacroiliac Tenderness n (\%) & $21(58.3 \%)$ & $14(38.8 \%)$ & 0.095 \\
\hline Oligoarticular involvement $\mathrm{n}(\%)$ & $18(50 \%)$ & $22(61.1 \%)$ & 0.114 \\
\hline Polyarticular involvement $\mathrm{n}(\%)$ & $5(13.8 \%)$ & $8(22.2 \%)$ & 0.257 \\
\hline MRI defined spinal involvement (Thoracal and/or lumbar) n (\%) & $13(36.1 \%)$ & $6(16.6 \%)$ & 0.017 \\
\hline MRI defined sacroiliac involvement $\mathrm{n}(\%)$ & $19(52.7 \%)$ & $8(22.2 \%)$ & 0.031 \\
\hline Uveitis $\mathrm{n}(\%)$ & $8(100 \%)$ & $0(0 \%)$ & 0.014 \\
\hline CRP $(\mathrm{mg} / \mathrm{dl})($ mean $\pm \mathrm{SD})$ & $3.53 \pm 3.55$ & $3.34 \pm 3.56$ & 0.809 \\
\hline $\mathbf{E S R}(\mathrm{mm} / \mathrm{h})($ mean $\pm \mathrm{SD})$ & $30 \pm 19$ & $28 \pm 25$ & 0.486 \\
\hline Anti-TNF treatment $\mathrm{n}(\%)$ & $30(83 \%)$ & $21(58 \%)$ & 0.061 \\
\hline
\end{tabular}

IQR:Interquartile range, CRP: C-Reactive protein, ESR: Erythrocyte sedimentation rate

patients were in remission and free of therapy at least 6 months.

\section{DISCUSSION}

In the presented single center study, we summarized the clinical characteristics, radiological findings and treatments of 72 ERA patients.

According to the ILAR criteria, JIA is divided into seven mutually exclusive subgroups and ERA is one of the most controversial subtypes of JIA, which differ from other types of inflammatory arthritis in genetic predisposition, pathogenesis, and risk of axial involvement [7]. Since the studies specifically performed on ERA are limited, the knowledge regarding ERA is based mainly on data from adults with spondyloarthritis (SpA) [8]. The largest study, which included 312 ERA patients, was reported from northern India in 2016 [9]. In this study, the mean age was 11.3 years, there was a male predominance (9:1), and $87 \%$ were human leukocyte antigen (HLA)-B27-positive. Consistently, in our cohort patients with ERA were also predominantly male (68.1\%), and HLA-B27-positive (50\%). The majority of our patients had arthritis and enthesitis at the time of diagnosis, and the most commonly affected joints were the knees and ankles. Enthesitis was most commonly presented at the patellar and the achilleas tendon. Nearly half of the patients had also sacroiliac tenderness at the time of diagnosis. These findings were in accordance with previously published series $[9,10]$.

ERA patients more commonly present with peripheral arthritis, and enthesitis, and less frequently spinal involvement compared to adult SpA [11]. The frequency of sacroiliitis in our patients with ERA was $37.5 \%$ and thoracolumbar involvement was $26.3 \%$. It was consistent with the results reported by Minden et al [12]. and Gmuca et al [13]. In most studies, higher frequencies of spinal involvement have been reported. In a series by Vendhan et al. among 58 ERA patients, 67\% showed lumbar spine involvement and $78 \%$ had concomitant sacroiliac joint involvement [14]. With the increased use of spinal MRI, which is $s$ a very sensitive technique for detecting early axial involvement, we noticed that the frequency of sacroiliitis and spinal involvement in patients with ERA is higher than we thought $[15,16]$.

When we compared the baseline clinical and laboratory characteristics of HLA-B27 positive and negative patients, we found that HLA-B27positive patients had significantly more enthesitis, MRI proven sacroiliitis, and MRI proven spinal involvement and acute anterior uveitis. Similar to the literature male predominance persisted in the 
HLA-B27 positive ERA patients. In the published series, the proportion of HLA-B27 positivity among ERA patients ranges from $45 \%$ to $89 \%$ [7, $9,10,17]$. To date, HLA-B27 positivity has been associated with different features of the disease. In a multicenter study it has been showed that, ERA patients who were HLA-B27- positive were older and male, with a higher active joint count, more sacroiliitis, and higher disease activity [13]. Several studies also showed that HLA-B27 positivity is a predictor of acute anterior uveitis, poor prognosis of disease and decreased likelihood of remission [7, 18-20].

As first-line therapy, all the ERA patients in our cohort received nonsteroid anti-inflammatory drugs (NSAID) and $90.2 \%$ received DMARDs as firstline therapies. The vast majority of them (70.8\%) failed to reach remission and needed anti-tumor necrosis factor- $a$ (TNF- $a$ ) therapy. Moreover, all our patients with axial involvement needed anti-TNF treatment. Since ERA patients tend to have higher disease activity, and risk of axial involvement, the treatment of ERA should be more aggressive than other subtypes of JIA [3, 8]. Previous studies have clearly shown that methotrexate alone is not an effective treatment in adult SpA [5, 21]. Recently, treatment recommendations for JIA patients have been published by the American College of Rheumatology (ACR) and it is recommended not to use methotrexate as a monotherapy for children with sacroiliitis [6]. In recent years, anti TNF agents have demonstrated an impressive efficacy on ERA [22]. Sustained efficacy of etanercept over 2 years has been reported in ERA patients [23]. In another retrospective study, it has been reported that remission has been achieved in $70 \%$ of patients with ERA at the 6th month of anti-TNF therapy [24]. In an open label multicenter phase III study, it has been shown that etanercept was effective and well-tolerated in pediatric patients with ERA for up to 12 weeks and ACR 30 was achieved by 88,6 $\%$ of subjects [25]. In a randomized, double-Blind, placebo-controlled multicenter study, it has been shown that adalimumab reduced the symptoms at week 12 in patients with ERA, and efficacy was sustained up to 52 weeks [26].

Our study had several limitations. Due to the retrospective nature of the study, the presence of symptoms was searched from the medical records and our sample size was limited at 72 patients.

In conclusion, we found that patients who were HLA-B27- positive tended to be male gender and had significantly more enthesitis, MRI proven sacroiliitis, MRI proven spinal involvement, and acute anterior uveitis, in comparison to patients who were HLA B27 negative. NSAIDs and DMARDs are the most prescribed medicines at the beginning of the disease, however, the vast majority of those patients needed anti-TNF agents to achieve remission. Since it is possible that ERA patients can be confused with other forms of childhood chronic arthritis at the beginning of the disease, carefully assessing those patients with concern for ERA is crucial for correct diagnosis, determining the expected prognosis, and making therapeutic decisions appropriately.

\section{CONFLICT Of INTEREST}

The authors declare no conflict of interest.
[1] Prakken B, Albani S, Martini A. Juvenile idiopathic arthritis. Lancet 2011; 377(9783): 2138-2149.

[2] Petty RE, Southwood TR, Manners P, et al. International League of Associations for Rheumatology classification of juvenile idiopathic arthritis: second revision, Edmonton, 2001. J Rheumatol 2004; 31(2): 390-392.

[3] Burgos-Vargas R. The juvenile-onset spondyloarthritides. Rheum Dis Clin North Am 2002; 28(3): 531-560, vi
[4] Weiss PF, Beukelman T, Schanberg LE, et al. Enthesitisrelated arthritis is associated with higher pain intensity and poorer health status in comparison with other categories of juvenile idiopathic arthritis: the Childhood Arthritis and Rheumatology Research Alliance Registry. J Rheumatol 2012; 39(12): 2341-2351.

[5] Poddubnyy D. Axial spondyloarthritis: is there a treatment of choice? Ther Adv Musculoskelet Dis 2013; 5(1): 45-54. 
[6] Ringold S, Angeles-Han ST, Beukelman T, et al. 2019 American College of Rheumatology/Arthritis Foundation Guideline for the Treatment of Juvenile Idiopathic Arthritis: Therapeutic Approaches for Non-Systemic Polyarthritis, Sacroiliitis, and Enthesitis. Arthritis Rheumatol 2019; 71(6): 846-863.

[7] Adrovic A, Barut K, Sahin S, et al. Juvenile Spondyloarthropathies. Curr Rheumatol Rep 2016; 18(8): 55.

[8] Weiss PF, Fuhlbrigge RC, von Scheven E, et al. Children with enthesitis-related arthritis could benefit from treatments targeted for adults with spondyloarthritis. Arthritis Care Res (Hoboken) 2020

[9] Srivastava R, Phatak S, Yadav A, et al. HLA B27 typing in 511 children with juvenile idiopathic arthritis from India. Rheumatol Int 2016; 36(10): 1407-1411.

[10] Nordal E, Zak M, Aalto K, et al. Ongoing disease activity and changing categories in a long-term nordic cohort study of juvenile idiopathic arthritis. Arthritis Rheum 2011; 63(9): 2809-2818.

[11] Gmuca S, Weiss PF. Evaluation and Treatment of Childhood Enthesitis-Related Arthritis. Curr Treatm Opt Rheumatol 2015; 1(4): 350-364.

[12] Minden K, Niewerth M, Listing J, et al. Long-term outcome in patients with juvenile idiopathic arthritis. Arthritis Rheum 2002; 46(9): 2392-2401.

[13] Gmuca S, Xiao R, Brandon TG, et al. Multicenter inception cohort of enthesitis-related arthritis: variation in disease characteristics and treatment approaches. Arthritis Res Ther 2017; 19(1): 84.

[14] Vendhan K, Sen D, Fisher C, et al. Inflammatory changes of the lumbar spine in children and adolescents with enthesitis-related arthritis: magnetic resonance imaging findings. Arthritis Care Res (Hoboken) 2014; 66(1): 40-46.

[15] Kurugoglu S, Kanberoglu K, Kanberoglu A, et al. MRI appearances of inflammatory vertebral osteitis in early ankylosing spondylitis. Pediatr Radiol 2002; 32(3): 191-194.

[16] Weiss PF, Xiao R, Biko DM, et al. Assessment of Sacroiliitis at Diagnosis of Juvenile Spondyloarthritis by Radiography, Magnetic Resonance Imaging, and Clinical Examination. Arthritis Care Res (Hoboken) 2016; 68(2): 187-194.
[17] Kunjir V, Venugopalan A, Chopra A. Profile of Indian patients with juvenile onset chronic inflammatory joint disease using the ILAR classification criteria for JIA: a community-based cohort study. J Rheumatol 2010; 37(8): 1756-1762.

[18] Burgos-Vargas R, Pacheco-Tena C, Vazquez-Mellado J. A short-term follow-up of enthesitis and arthritis in the active phase of juvenile onset spondyloarthropathies. Clin Exp Rheumatol 2002; 20(5): 727-731.

[19] Berntson L, Damgard M, Andersson-Gare B, et al. HLA-B27 predicts a more extended disease with increasing age at onset in boys with juvenile idiopathic arthritis. J Rheumatol 2008; 35(10): 2055-2061.

[20] Chang JH, McCluskey PJ, Wakefield D. Acute anterior uveitis and HLA-B27. Surv Ophthalmol 2005; 50(4): 364388.

[21] Haibel $H$, Brandt HC, Song $I H$, et al. No efficacy of subcutaneous methotrexate in active ankylosing spondylitis: a 16-week open-label trial. Ann Rheum Dis 2007; 66(3): 419-421.

[22] Katsicas MM, Russo R. Biologic agents in juvenile spondyloarthropathies. Pediatr Rheumatol Online J 2016; 14(1): 17.

[23] Henrickson M, Reiff A. Prolonged efficacy of etanercept in refractory enthesitis-related arthritis. J Rheumatol 2004; 31(10): 2055-2061.

[24] Sulpice M, Deslandre CJ, Quartier P. Efficacy and safety of TNFalpha antagonist therapy in patients with juvenile spondyloarthropathies. Joint Bone Spine 2009; 76(1): 2427.

[25] Horneff G, Burgos-Vargas R, Constantin T, et al. Efficacy and safety of open-label etanercept on extended oligoarticular juvenile idiopathic arthritis, enthesitis-related arthritis and psoriatic arthritis: part 1 (week 12) of the CLIPPER study. Ann Rheum Dis 2014; 73(6): 1114-1122.

[26] Burgos-Vargas R, Tse SM, Horneff G, et al. A Randomized, Double-Blind, Placebo-Controlled Multicenter Study of Adalimumab in Pediatric Patients With Enthesitis-Related Arthritis. Arthritis Care Res (Hoboken) 2015; 67(11): 15031512. 